\title{
Explaining Energy Conservation and Environmental Citizenship Behaviors Using the Value-Belief-Norm Framework
}

\author{
Felix Kwame Yeboah' \\ Department of Agricultural, Food and Resource Economics \\ Michigan State University, East Lansing, United States
}

Michael D. Kaplowitz

Department of Community Sustainability

Michigan State University, East Lansing, United States

\section{Abstract}

Despite decades of research, uncertainty remains about what motivates individuals to engage in pro-environmental behavior. The multifaceted and complex nature of energy conservation, like other forms of pro-environmental behavior, still poses a challenge to efforts at accurately explaining or predicting it. This paper examines the extent to which variables in the value-beliefnorm framework are able to explain engagement in energy conservation and environmental citizenship behavior in an institutional setting. The results indicate that value-belief-norm constructs, which largely reflect environmental considerations, were more successful at explaining subjects' pro-environmental citizenship behavior than their energy conservation behavior. Individuals' personal norms and self-transcendence values were found to be the most influential precursors of their pro-environmental behavior. Subjects' behaviorspecific beliefs also influenced their pro-environmental behavior and were mediated by their personal norms. The implications of our results for the design of pro-energy conservation intervention are discussed.

Keywords: beliefs, energy conservation, environmental citizenship, norms, self-enhancement value, self-transcendence value

1 Corresponding author: yeboahfe@msu.edu. 


\section{Introduction}

Events such as the British Petroleum oil spill in 2010 in the Gulf of Mexico and the Fukushima Daiichi nuclear disaster in Japan in 2011 highlight some of the social, economic, and environmental challenges associated with energy production and use. At the same time, scientific studies (e.g., IPCC, 2014) increasingly show that man-made climate change is a problem that will adversely affect people and the environment. Achieving a sustainable energy future with adequate environmental protection has again become part of debates in politics, education, business, and everyday life (Herring, 2006). Increased energy efficiency and energy conservation, among other things, are perceived to have promise as parts of a strategy to help reduce energy consumption and greenhouse gas generation.

Current efforts at improved energy conservation have primarily focused on technology-based solutions. Nevertheless, inventing better technology alone is likely to prove insufficient for reducing individuals' energy consumption since efficiency gains from such technologies are often offset by consumption growth resulting from consumers' increased acquisition and use of more electric appliances (Midden et al., 2007). Also, the effectiveness of technologybased solutions has been undermined by consumers' reluctance to invest in low-emission technologies over less expensive and more established products (Brown, 2001). More efficient energy use likely will require behavioral change to adopt and maintain improved technologies and practices. Promoting such behavioral changes may benefit from a better understanding of the social systems and underlying factors of human behaviors that shape energy consumption (Steg and Vlek, 2009).

This study therefore focuses on some underlying factors influencing energy conservation behavior (ECB) and environmental citizenship behavior (EAB) of members within a large institution. Developing a better understanding of how the values, beliefs, and norms of constituent members of institutions shape energy conservation and pro-environmental behavior may prove useful in helping to frame and craft effective long-term strategies to promote pro-energy conservation behavioral change.

\section{Background}

Despite decades of research, considerable uncertainty still remains about what motivates individuals to engage in energy conservation and other pro-environmental behavior. Researchers have investigated the role of environmental knowledge (e.g., Abrahamse et al., 2007; Bradford 
\& Fraser, 2008), environmental values and attitudes (e.g., Milfont et al., 2010; Stern, 2000), and demographic characteristics and contextual factors (e.g., Clark et al., 2003; Schultz \& Oskamp, 1996) as determinants of pro-environmental behavior. Several theoretical frameworks have also been developed to integrate various combinations of these factors in attempts to guide the design of behavioral interventions. However, the multifaceted and complex nature of energy conservation, like other forms of pro-environmental behavior, still poses a challenge in efforts to accurately explain or predict such behavior.

\section{Individuals' environmental/ecological insights and concerns}

It is important to keep in mind how individuals' environmental and ecological insights and concerns arise in the first place. Empirical evidence suggests that individuals' ecological and environmental concerns arise and are influenced by the interplay of diverse factors. Some studies point to people's experiences as a key source of their environmental concern (Nisbet et al., 2009). For instance, affinity, interest, indignation, and positive nature experiences have been found to be predictive of nature protective behavior (Kals et al., 1999; Nisbet et al., 2009). Maiteny (2002) provides some evidence that emotional involvement and experience are central to individuals' sustained pro-environmental values and behavior. However, particular experiences may result in quite different meanings across individuals.

Kollmuss and Agyeman (2002) demonstrate how the meanings that individuals construct to make sense of significant formative and transformative experiences play a powerful part in "loosening" internal constraints to changing old habits and generating impetus for new action. While experiences are essential, it appears that the framing of such experiences or the meaning derived from them leads to the formation of individuals' environmental concern. Those experiences may induce concern about the environment per se in cases where the individual anticipates catastrophic effects from environmental degradation. Similarly, experiences may also create concerns about personal well-being as a result of situations in which an individual believes that behaving in environmentally benign ways enhances their sense of self-worth and self-esteem (Maiteny 2002).

Environmental concern may also arise and be transmitted through social modeling. People may become altruistic (toward the environment) by imitating or learning from their role models, especially from family and parents (Mattis et al., 2009; Mikulincer and Shaver, 2005). For instance, a child raised to be kind to the environment may grow up with that character trait. Similarly, individuals may develop a sense of environmental concern as a result of social compulsion or pressure arising from their association with people who are environmentally 
friendly. Lee et al. (2005) also point to the role of spiritual and religious beliefs as sources of environmental concern; that spiritual and religious beliefs or ideologies that place a premium on caring for others and nature may inform a greater sense of personal responsibility toward the environment.

While a complete treatment of how ecological insights and concerns arise in the first place is beyond the scope of this paper, it is important to remember that they arise within individuals who hold them in different ways and are developed within society, families, and everyday settings.

\section{Value-belief-norm theory}

Building on previous theories of environmentalism, Stern and his colleagues (1999) developed the value-belief-norm (VBN) theory, which links value theories (Schwartz, 1992, 1994; Stern \& Dietz, 1994), environmental beliefs (Dunlap \& Van Liere's, 1978, new environmental paradigm), and a norm-activation model (Schwartz, 1977) into a causal chain. The VBN theory posited that individuals' values drive beliefs and, in turn, norms which impact individuals' behaviors. Distinguishing between four types of pro-environmental behaviorenvironmental activism (active involvement in environmental organizations or demonstrations), non-activist behavior in the public sphere (support or acceptance of public environmental policies), private-sphere environmentalism (the purchase, use, and disposal of personal and household products that have environmental impact), and organizational actions that promote environmental protection (design of environmentally benign products) - the authors argued that their model could explain behavior undertaken with pro-environmental intent. To date, the VBN theory has provided a powerful explanatory framework of a variety of ecological behavior including ecological citizenship, political support, and private sector actions. Evidence has shown that, depending on the type of behavior (i.e., private-sphere behavior, policy support action, or environmental citizenship), the VBN model can effectively explain $19 \%$ to $35 \%$ of the variance in respondents' self-reported pro-environmental behavior (Steg et al., 2005; Stern et al., 1999). Given the weight of previous VBN research, we adopt the VBN theoretical framework for our study of individual-level factors influencing two forms of non-activist, pro-environmental behavior$\mathrm{ECB}$ and $\mathrm{EAB}$ - in a large, institutional context.

\section{Previous research using the value-belief-norm framework}

Researchers have used the VBN model in its entirety or parts thereof (i.e., subsections of it) in a range of investigations including consumer behavior (Kaiser et al., 2005), willingness to sacrifice (Stern et al., 1999), willingness to 
reduce car use (Nordlund \& Garvill, 2003), acceptability of energy policies (Steg et al., 2005), and consumers' adoption of high involvement eco-innovation (Jansson et al., 2011; see also Andersson et al., 2005; Ibtissem, 2010; Kaiser et al., 2005). A few reported studies have used VBN theory as part of efforts to explore and explain behaviors related to energy conservation. For instance, Steg and his colleagues (2005) applied the full VBN model in a household setting to explain acceptability of energy policies aimed at reducing carbon dioxide emissions. Their results confirmed the causal order of the variables in the VBN theory, with the full model explaining about $32 \%$ of the variance in acceptability judgments. Similarly, Ibtissem (2010) adopted subsections of the VBN model to explore the extent to which ECB is influenced by norms. His study demonstrated the efficacy of the VBN theory to explain ECB among the Tunisian public. Nevertheless, virtually all of these studies have been conducted using household surveys, in household settings. Only one known reported study has drawn on VBN theory to examine energy conservation in an institutional setting (Scherbaum et al., 2008). Scherbaum and colleagues (2008) examined individual-level factors related to employee ECB in a large midwestern university and found environmental personal norms (PN) to be a key predictor of self-reported ECB and behavioral intent as well as a mediator between environmental world views and ECB. However, these authors employed only sections of the VBN theory, excluding the values and some of the belief components of the model. Therefore, the comparability and generalizability of VBN measures as well as the role of individuals' VBN on ECB in an institutional context remains an unanswered question.

\section{Study focus}

In this study, we focus on the influence of individual-level VBN factors on two forms of non-activist, pro-environmental behavior - ECB and EAB - that were identified by an institution as central to its sustainability goals. While ECB (e.g., reducing electricity consumption) has direct environmental impacts, EAB (e.g., voting for pro-environmental candidates) positively affects the environment indirectly via public policy. Relative to $\mathrm{ECB}, \mathrm{EAB}$ often accrues high collective rather than direct individual benefits. For instance, voting for pro-environmental candidates may result in increased environmental legislation, providing environmental protection for all. In contrast, individual actions to conserve energy may result in direct financial savings and increased personal comfort in addition to such collective benefits as improvements in environmental quality. This suggests that, unlike EAB, ECB may be motivated by an array of factors which may not necessarily be borne out of environmental concerns. Thus, as VBN constructs principally reflect respondents' environmental considerations, the model is likely to evidence different relative effects on ECB and EAB unless they are both principally motivated by environmental considerations. In fact, 
while much research has shown that values are related to environmental citizenship (Stern et al., 1999), some studies indicate that personal values tend to have no effect or are weakly associated with intention to reduce energy use (e.g., Abrahamse, 2007; Neuman, 1986). However, to date, no empirical study has examined such potential differences in determinants on these two forms of pro-environmental behavior.

\section{Research hypotheses}

We hypothesized that respondents' VBN constructs will have different effects on their ECB and their EAB (Hypothesis 1). Furthermore, we hypothesized that respondents' environmental values would be positively related to their pro-environmental beliefs (Hypothesis 2) and, in turn, their environmental PN (Hypothesis 3). Additionally, we expected respondents' PN to be related to both their ECB and their EAB (Hypothesis 4) while mediating the relationship between environmental beliefs and their energy conservation and their environmental citizenship (Hypothesis 5). Finally, we hypothesized being able to detect direct effects (in addition to indirect effects) of respondents' environmental values and beliefs on ECB and EAB (Hypothesis 6).

\section{Materials and methods}

\section{Survey sample and response rate}

Participants in this study were part of a random sample of 15,652 students, faculty, and staff drawn from the official records of Michigan State University, a large, research-intensive university in the United States Midwest. Every member of the university population has an e-mail address, access to the Internet, and regularly uses e-mail and Web-based forms to conduct university business. Roughly $30 \%$ of the campus population was invited to participate in a Web-based campus planning survey. The study population, while not representative of the general population, is typical of other 'special populations' used for experimental inquiries. Moreover, we do know some of the sample's demographic characteristics and those of the target population. Our use of a Webbased survey with a probability-based sample avoided many pitfalls associated with online Web survey panels (Baker et al., 2010). Members of the random sample were invited to participate in the survey as many as three times, in the event that they had not responded to a previous invitation. After accounting for undeliverable and incorrect addresses, the overall survey response rate was $24.9 \%$ with 3,896 respondents completing the survey (AAPOR, 2009). This response rate is in line with response rates for other Web or Internet surveys (Cook et al., 2000; Kaplowitz et al., 2004; Sheehan, 2001). 


\section{Survey design}

The survey instrument was designed, developed, and implemented following best practices, principles and guidelines of Dillman's Tailored Design Method (Dillman, 2007), Presser et al. (2004), and Couper (2008). The instrument was primarily aimed at helping to provide input concerning the institution's energy use, conservation, and generation options. Therefore, the researchers first conducted individual interviews with key informants concerning energy options and barriers with university administrators, consulting engineers, and personnel. Next, focus group discussions were held with members of the target population. The findings from these preliminary studies formed the baseline knowledge for the initial survey design. An iterative pretesting and revision process of the survey instrument that included draft value, belief, norm, and energy behavior questions followed. The final survey instrument consisted of multiple sections including an inquiry of respondents' policy preferences and questions assessing respondents' values, attitudes, and energy use behavior. Results of the energy use, conservation, and alternative questions are reported elsewhere (Komarek et al., 2011).

\section{Measurement}

Typically, the use of established compound measures of VBN components such as the new environmental paradigm scale requires researchers to include a large number of survey items in their studies' questionnaires. However, considering the time and cognitive burdens on our respondents as well as the limited questionnaire space in our large campus planning survey, we used truncated versions of the VBN constructs in our analysis. Using truncated versions of environmental attitudinal scales has proven to be effective in other studies (e.g., Bord et al., 2000; Scherbaum et al., 2008). Next, we discuss the measures used for each construct.

\section{Values}

Study participants' value systems were assessed using a shortened version of Schwartz's (1992) universal value scale. Reduced forms of the Schwartz value scale were successfully used in previous studies (Jansson et al., 2011; Nordlund \& Garvill, 2002; Steg et al., 2005; Stern et al., 1998). For our study, we focused on measures of values related to respondents' dimensions of self-enhancement (SE) and self-transcendence (ST) because, among other things, they were previously reported to be related to pro-environmental behavior (Karp, 1996; Nordlund \& Garvill, 2002; Stern et al., 1998) and also because they neatly embody the oft-used biospheric-altruistic-egoistic value classification (Stern et al., 1995). According to Schwartz (1992), in any culture, individual values will fall along 
a dimension of SE to ST reflecting the distinction between values oriented toward the pursuit of self-interests even at the expense of others and values related to concern for the welfare of others, close and distant, and of nature.

Initial drafts of our questionnaire used items with single-word representations of Schwartz's value items as other researchers have done (e.g., Karp, 1996). However, during pretesting the feedback concerning this formulation of the value items revealed that participants had too many questions about those items and repeatedly asked for explanations of what each value term meant. As a result, the value survey items were redrafted (and pretested) until brief statements adapted from Schwartz (1992) were developed for the measures of value items.

In the end, measures of nine values were included in the survey instrument (Table 1). Participants were asked to indicate their level of agreement with value statements using a five-point Likert-type response scale ranging from 1 strongly disagree to 5 strongly agree. Based on a factor analysis, the responses to these items were grouped into two factors - six of the items loading on a single factor reflecting measures of ST values (e.g., unity with nature, helpfulness, social justice, equality) and three items reflecting measures of SE values (authority, social power, wealth). All six items in the ST scale were interrelated and showed sufficient internal consistency in the reliability analysis (Cronbach $\alpha=0.73$ ). This was also true for the three items in the SE values scale, which demonstrated more modest internal consistency (Cronbach $\alpha=0.43$ ). The mean score of each value scale item was used in the analysis. Table 1 presents the value items and their factor loadings. Overall, respondents expressed higher levels of ST values $(M=4.02, S D=.52)$ than SE values $(M=3.10, S D=.58)$. That is, on average, respondents were less concerned about pursuing self-interests relative to their concern about the welfare of other people and nature.

Table 1. Value orientation items

\begin{tabular}{|c|c|c|}
\hline \multirow{2}{*}{} & \multicolumn{2}{|c|}{ Factor loadings } \\
\cline { 2 - 3 } & $\mathbf{1}$ & \\
\hline Self-transcendence (ST) values & & \\
\hline It is important to help and care for people around me & .754 & \\
\hline I take action to improve well-being of people I do not know & .657 & \\
\hline I am willing to sacrifice for good of those around me & .654 & \\
\hline It is important that every person care for nature & .634 & \\
\hline It is important that every person in the world be treated equally & .583 & \\
\hline My responsibility is to provide only for my family and myself & .572 & .778 \\
\hline Self-enhancement (SE) values & & \\
\hline It is important that people recognize my achievements & & \\
\hline It is important to be respected by others & & .579 \\
\hline It is important to have a lot of money and expensive things & & \\
\hline
\end{tabular}




\section{Beliefs}

Typically, the "new environmental paradigm" scale (Dunlap \& Van Liere, 1978) and its subsequent revisions such as the "new ecological paradigm" (NEP) scale (Dunlap et al., 2000) have been used as measures of respondents' ecological beliefs. Following Kotchen and Moore (2007), we measured the NEP of our respondents using a simplified measure of five items (Table 2). Each item in our study's NEP scale corresponds with one of the reported five facets of the NEP world view: (1) reality of limits to growth, (2) anti-anthropocentricism, (3) fragility of nature's balance, (4) rejection of exceptionalism, and (5) possibility of an ecological crisis (Dunlap \& Van Liere, 1978; Dunlap et al., 2000). Study participants were asked to rate their level of agreement with our five NEP items using a five-point Likert-type scale ranging from $1=$ strongly disagree to 5 strongly agree. A higher average score for these five items reflected a stronger ecological view. Results of these items were correlated and the additive scale had a Cronbach alpha reliability of 0.66. Respondents' mean scores on NEP items were used in subsequent analyses $(M=3.63, S D=0.71)$.

Table 2. Belief and norm items

\begin{tabular}{|l|}
\hline New ecological paradigm (NEP) scale items, Cronbach $a=0.66$ \\
\hline The so-called 'ecological crisis' facing humankind has been greatly exaggerated $(\mathrm{R})$ \\
\hline The balance of nature is strong enough to cope with the impacts of modern industrial nations (R) \\
\hline Earth is like a spaceship with limited room and resources \\
\hline Plants and animals have as much right as humans to exist \\
\hline Human ingenuity will ensure that we do not make Earth unlivable (R) \\
\hline Awareness of consequences (AC) belief item \\
\hline Conserving energy helps to reduce the effect of climate change \\
\hline Ascription of responsibility (AR) belief item \\
\hline My energy use makes a noticeable contribution to climate change \\
Energy use personal norms (PN) \\
\hline I feel guilty when I waste energy
\end{tabular}

Note: $(R)$ survey items were reverse coded.

We used single survey items to measure respondents' beliefs regarding the consequences of their actions as well as their feelings of responsibility for causing (or averting) the consequent environmental problems related to energy conservation and pro-environmental behavior. Subjects were asked to indicate the extent to which they agreed, using a 5-point scale $(1=$ strongly disagree to 5 = strongly agree), with statements designed to reflect their awareness of consequences (AC) and ascription of responsibility (AR) regarding energy use (Table 2). The statement used to assess AR beliefs reflected the extent to which respondents felt responsible for the problems associated with energy use, 
including climate change. The statement concerning AC measured the extent to which respondents believed their energy conservation could reduce the effect of climate change. On average, respondents were generally aware of the environmental consequences of their energy use $(M=3.45, S D=1.01)$ and felt somewhat responsible for the energy-related problems $(M=3.18, S D=.96)$.

\section{Norms}

Norms are typically measured using statements that respondents are asked to evaluate or rate. For example, Steg et al. (2005) asked respondents to rate a series of statements representing normative perceptions about energy use in efforts to understand normative factors influencing the relative acceptability of energy policies. We used an individual survey item concerning energy conservation to assess respondents' $\mathrm{PN}$ regarding energy conservation. The survey item presented a statement reflecting the extent to which the subject feels a moral obligation to conserve energy: I feel guilty when I waste energy (Table 2). Study participants were asked to indicate the extent to which they agreed with the statement using a scale ranging from $1=$ strongly disagree to $5=$ strongly agree. On average, participants reported feeling somewhat obligated to conserve energy $(M=3.77, S D=.87)^{2}$

\section{Behaviors}

In our study setting, two forms of behavior-energy conservation and environmental citizenship - were central to our substantive inquiry and the institution's sustainability goals. After pretesting alternative forms of survey items, the final questionnaire included seven items that asked respondents about self-reported behaviors and behavioral intentions. Responses to these items were used to gauge subjects' habitual and purchase-related ECBs and measure their EAB (Table 3). For the ECB items, respondents indicated their frequency of such behavior using a five-point Likert-type scale with 1 representing never and 5 representing always. For EAB items, respondents expressed their level of agreement with the items using a five-point scale from $1=$ strongly disagree to 5 strongly agree. Factor analysis of the behavior items revealed two main factors reflecting the two hypothesized components of behavior. The first factor consisted of three items reflecting $\mathrm{EAB}$ and yielded an additive scale with a Cronbach's alpha of 0.70 in the reliability analysis. The second factor, energy use behavior, comprised three items concerning participants' habitual energy use and one item concerning purchasing related to energy conservation. The energy use behavior factor items were interrelated with an additive scale having a Cronbach's alpha reliability of 0.51 (see Table 3 for factor loadings).

2 Note that measures of $\mathrm{AC}, \mathrm{AR}$, and $\mathrm{PN}$ were worded to capture the general environmental concerns associated with energy use, which we believe also underlie their engagement in EAB. 
Table 3. Behavior items

\begin{tabular}{|l|c|c|}
\hline & \multicolumn{2}{|c|}{ Factor loading } \\
\cline { 2 - 3 } & $\mathbf{1}$ & $\mathbf{2}$ \\
\hline Environmental citizenship behavior (EAB) & & \\
\hline I adjust my purchases based on environmental concerns & .828 & \\
\hline I participate in activities that promote environmental protection & .793 & \\
\hline I consider an elected official's environmental record before voting & .734 & \\
\hline Energy conservation behavior (ECB) & & \\
\hline Turn off computers, printers, etc. overnight & & .694 \\
\hline Unplug electrical appliances when not in use & & .678 \\
\hline Turn off lights in unoccupied rooms & & .582 \\
\hline Purchase energy-efficient appliances (e.g., EPA Energy Star) & & .560 \\
\hline
\end{tabular}

\section{Data analysis}

Survey data from the 3,896 respondents provides the basis for empirical analysis of our hypotheses. Using principal component factor analysis procedures and reliability analysis tests, scale measures for each construct were computed as the mean score of all valid responses to the items within a factor (Brown, 2012). Next, a series of regression analyses based on the VBN model were run to test the study's hypotheses.

First, the measures of $\mathrm{ECB}$ and $\mathrm{EAB}$ were regressed on the set of predictors in the basic VBN causal model (PN, AR, AC, NEP, and ST and SE values) (Table 4). Then, each variable in the posited causal chain (SE or ST values $\rightarrow$ NEP $\rightarrow$ AC $\rightarrow$ AR $\rightarrow \mathrm{PN}$ ) was regressed (stepwise) onto the preceding variables in the model. This enabled us to test whether variables directly affected variables further down the causal chain when intermediate variables are controlled for, and follows the approach used by Steg et al. (2005) and Stern et al. (1999).

To establish a causal link, intermediate variables must have some mediating effect on variables next to them in the model. We follow Baron and Kenny's (1986) approach to test for these mediation effects. As Baron and Kenny (1986) suggest, mediation occurs when four conditions are satisfied: (1) the independent variable significantly affects the mediator; (2) the independent variable significantly affects the dependent variable in the absence of the mediator; (3) the mediator has a significant unique effect on the dependent variable; and (4) the effect of the independent variable on the dependent variable shrinks 
upon the addition of the mediator to the model. Therefore, we ran a series of regression analyses to test for these conditions. Then, following Dudley et al. (2004), we used a Sobel test to test the hypothesis that the mediation effect is equal to zero (see also Preacher \& Leonardelli, 2010). The Sobel test enabled us to determine the presence of a mediating effect of the mediator variables in the model. When mediation was found to be significant, we computed the amount of explained variance accounted for by the mediating variable (see Jasti et al., 2008, for detailed procedure).

\section{Results}

\section{Environmental citizenship, energy conservation, and value-belief-norm theory}

Table 4 presents the unstandardized regression coefficients of models of EAB and ECB using our predictor variables based on the VBN theory. As the results illustrate, to varying degrees, the VBN framework was useful in explaining some of the variance in EAB and ECB. The results suggest that our VBN model was more successful explaining variation in participants' EAB than their ECB. Overall, the complete set of predictor variables in our VBN model accounted for $57.7 \%$ of the variance in $\mathrm{EAB}$ and only $7.9 \%$ of the variance of ECB (Hypothesis 1).

The model's PN variable had a large, direct effect on respondents' EAB; PN accounted for about $27.2 \%$ of EAB's explained variance (bivariate correlation between $\mathrm{PN}$ and $\mathrm{EAB}$ was 0.52 ) when variables further up the chain were excluded from the regression model. That is, those respondents reporting higher levels of PN were associated with higher levels of engagement in EAB. This was also found to be true for respondents' ECB; respondents' PN accounted for more than half $(4.2 \%)$ of the total explained variance $(7.9 \%)$ in ECB. These finding are consistent with and support the hypothesis that there are direct, positive effects of PN on subjects' EAB and ECB (Hypothesis 4). 


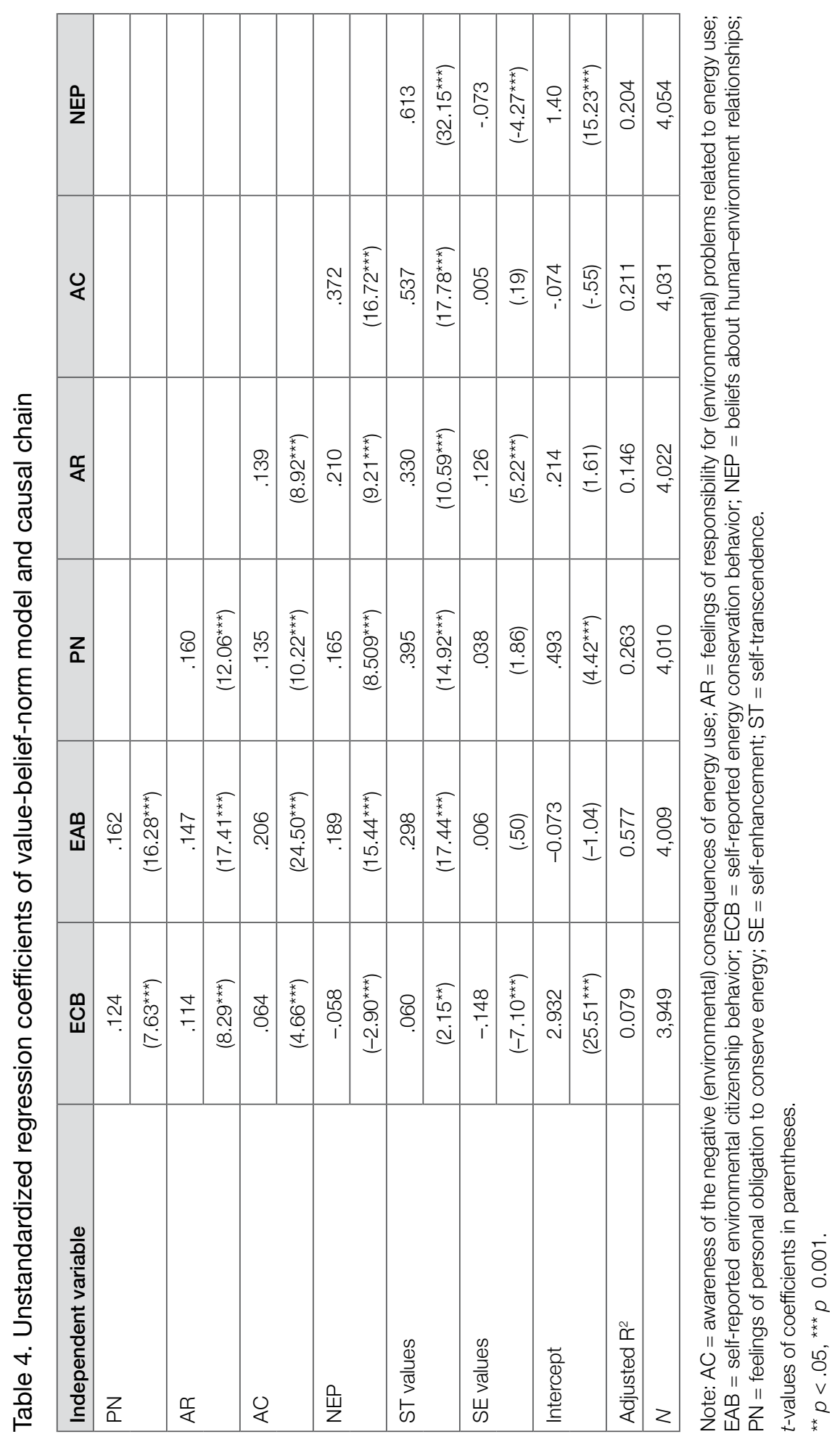


Also, the PN variable was not the only VBN construct variable that appears to have a direct effect on subjects' EAB and ECB. As illustrated in Table 4, all of the other VBN construct variables preceding $P N$ in the causal chain had significant direct effects on ECB and EAB. For instance, respondents' ST values, a previously reported precursor of pro-environmental behavior, had positive direct effects on both ECB and EAB, thus supporting Hypothesis 6. The results indicate that respondents' ST values were the most influential factor in activating $\mathrm{PN}$, supporting Hypothesis 3. Our results show that respondents' ST values indeed had the largest direct effect on AC, AR, and NEP beliefs (Hypothesis 2). On the other hand, respondents' SE values were less consistently related to the dependent variables. For instance, SE values appear to have no effect on $\mathrm{EAB}, \mathrm{PN}$, and AC while only marginally influencing ECB, NEP, and AR (Table 4). The results also show that subjects' NEP, AC, and AR beliefs have a significant direct effect on EAB and ECB (Hypothesis 6).

\section{Causal chain of value-belief-norm components}

The results appear to confirm the causal order suggested by the VBN framework. All of the variables were significantly related to the next variable in the causal chain. The Sobel test results reveal that the effect of almost all the mediator variables was significantly different from zero at the $95 \%$ confidence interval with the exception of NEP mediating SE and AC beliefs. This implies that the mediator construct variables had at least a partial mediating effect on the variable directly following it in the model. Based on the Sobel test results, it appears that the relationships between respondents' feelings of responsibility for energy-related problems (AR) and participants' EAB and ECB were mediated by respondents' $\mathrm{PN}, t=18.59, p<.0001$ and $t=8.766, p<.0001$ respectively (Hypothesis 5).

Our results met the four conditions suggested by Baron and Kenny (1986) to establish mediation for PN, AR, AC, and NEP. For example, in the test of PN as a mediator variable between $\mathrm{EAB}$ and $\mathrm{AR}$, our analysis revealed a significant effect of AR on PN, $F(1,4,027)=510.73, p<.0001$. Also, EAB was significantly affected by $\operatorname{AR}[F(1,4,038)=1,102.39, p<.0001]$ and $\mathrm{PN}[F(1,4,031)=1,504.43$, $p<.0001]$. Finally, significant impacts were found in the regression of EAB on AR beliefs and PN, $F(2,4,023)=1,159.67, p<.0001$. That is, although both $\mathrm{PN}$ and AR beliefs contributed significantly to respondents' $\mathrm{EAB}$, the effect of AR beliefs on $\mathrm{EAB}$ was reduced when $\mathrm{PN}$ was controlled for, suggesting a partial mediating role of PN. These conditions also hold true for the relationship between ECB and AR with PN as a mediator. A calculation of the amount of mediation indicates that PN accounted for about $29.6 \%$ of the effect of AR on $\mathrm{EAB}$ and about $26.7 \%$ of the effect of AR on ECB. We conducted similar analyses for the remaining variable links in the VBN chain to test for mediation effects. 
For the sake of space and brevity, we focus on reporting the Sobel test and the amount of mediation occurring for the remaining links in the causal chain for which significant mediation was established.

The results of the Sobel test suggest that the relationship between AC and PN was mediated by AR $(t=12.98, p<.0001)$ and that AC, in turn, mediated the relationship between NEP and AR $(t=11.203, p<.0001)$. We also found that AR mediated about $20.4 \%$ of the effect of AC on PN while AC accounted for about $26 \%$ of the effect of NEP on AR. Likewise, NEP was found to mediate the relationship between ST and $\mathrm{AC}(t=16.18, p<.0001)$, accounting for about $29.6 \%$ of the effect of ST on AC. On the other hand, the role of NEP as a mediator between SE and AC was not established. Individuals' SE values had no significant direct effect on their AC $(t=0.113, p<.910)$. Even when NEP is controlled for, our SE values did not significantly affect $\mathrm{AC}(t=1.249, p<.212)$, thereby violating Baron and Kenny's (1986) conditions for mediation. Hence, the mediation role of NEP between SE values and AC beliefs was not established.

\section{Discussion and conclusion}

As part of efforts to inform the design of effective strategies to promote proconservation behavior at a large academic institution, this study focused on developing an understanding of underlying factors driving ECB and EAB of the members of the institution. We first examined the viability of the VBN framework to illuminate these two forms of non-activist behavior, cited as central to the institution's sustainability goals, and then identified those factors that significantly influence those two forms of behavior in our population.

Regarding the viability of the VBN framework, the results suggest that VBN theory successfully helps explain ECB and EAB, to varying degrees, of university constituents. Our model explained more variance in participants' reported EAB as a function of VBN constructs than the observed variance in reported ECB. The reported disparity in explained variance supports our hypothesis that the two forms of non-activist behavior examined are motivated by a different array of factors and hence the VBN constructs will reveal different effects on them. It appears that EAB is largely dependent on respondents' environmental considerations. Hence, the relatively large explained variance reported may be a reflection of the VBN constructs used in our model, which largely tapped respondents' general environmental concerns, beliefs, and norms. Similarly, the relatively attenuated effect of VBN constructs on explaining ECB might imply that environmental considerations were not key determinants of the reported behavior. This appears to be supported by our finding of a negative relationship between respondents' NEP and respondents' self-reported energy conservation 
activities. Perhaps other factors besides environmental considerations (e.g., convenience of the activity, social pressure) may be driving the reported behavior and these factors may not be directly captured in a VBN model. In such a case, the attitudinal constructs in the VBN model will be expected to have an attenuated effect on energy conservation as our results and other studies suggest (Abrahamse, 2007; Diekmann \& Preisendörfer, 2003). It is important to note that other studies have also reported lower predicting power of the VBN model for energy conservation (e.g., Abrahamse, 2007; Ibtissem, 2010). Those authors attribute their findings to the inability of the VBN model to account for external factors that are not psychological in nature.

Moreover, our study results confirm the causal order of all the variables of VBN theory as they relate to pro-environmental behavior. Moving from the relatively stable personal values to general beliefs about human-environment relations to more specific beliefs and norms for actions that correspond with pro-environmental behavior, the VBN construct variables in our model were significantly related to the next variable in the causal chain. Also, in line with results from previous studies (Nordlund \& Garvill, 2003; Steg et al., 2005), the hypothesized mediation effects of most of the variables were confirmed. PN mediated the relationship between AR beliefs and the two forms of non-activist behavior - energy conservation and environmental citizenship-while AR beliefs in turn mediated the relationship between AC beliefs and PN. Similarly, the results confirmed the mediating role of AC and NEP beliefs for the relations between AR and NEP beliefs and AC beliefs and ST values respectively. These findings demonstrate the applicability of the VBN framework for examining pro-environmental behavior in an institutional context.

In exploring the factors underlying these two forms of behavior, our results revealed that high levels of $\mathrm{EAB}$ and $\mathrm{ECB}$ were associated with stronger PN. Individuals' $\mathrm{PN}$ accounted for more than half of the variance in $\mathrm{EAB}$ and $\mathrm{ECB}$ in the model. Also, ST values were found to be most influential in activating PN while having a strong direct effect on both EAB and ECB. That is, individuals with ST-value orientation were more likely to feel guilty for wasting energy and more likely to engage in ECB and EAB. This fits with the wide array of research that has found ST values to be positively related to pro-environmental behavior, including energy conservation (Dietz et al., 2005; Karp, 1996; Poortinga et al., 2004; Schultz \& Zelezny, 1999; Stern et al., 1993). It also reflects the stable nature of the relationship between environmental values and pro-environmental behavior, which cannot easily be moderated by interventions.

In addition, ST-value orientation was found to be associated with a favorable view of the human-environment relations (NEP) as well as specific AC and AR beliefs concerning energy conservation. On the other hand, the results suggest that subjects' SE values have a more complex role in influencing pro-environmental 
behavior. As expected, SE was negatively related to ECB and NEP. Nevertheless, it generally proved ineffective as a predictor of EAB, AC beliefs, and PN and it unexpectedly had a positive relation with AR beliefs. Our finding of a complex role of SE values converges with the findings of Ibtissem (2010) but contrasts with the findings of Steg et al. (2005). Obviously, more work is needed in this area including better tests of alternative measures of relevant constructs.

Furthermore, the results show that respondents who feel that their energy use makes a noticeable contribution to climate change (AR beliefs) are associated with higher levels of awareness of the consequences of their energy use (AC beliefs). Such respondents are more likely to feel guilty for wasting energy (PN). That is, as respondents are increasingly aware of the negative environmental consequences of their energy use, the more they assume responsibility for the negative environmental problems related to their energy use, and the more dutiful they feel about working to reduce their energy consumption.

While we need to exercise caution in drawing conclusions about causality based on these associations, the findings provide some insights toward crafting effective strategies to promote environmental citizenship and energy conservation in institutional settings. First, they suggest that institutional education programs that strengthen individuals' ST values while highlighting the negative impacts of individuals' energy use may be able to induce a sense of responsibility and activate personal moral norms needed to initiate pro-ECB and $\mathrm{EAB}$. To be effective, messages from such education programs need to be framed to reflect and appeal to the values of the recipients (Schultz \& Zelezny, 2003) while providing information on specific behavioral changes they could undertake to conserve energy and protect the environment. In other words, education programs may need to equip the target group with the why, what, and how of the behavior in question to initiate the desired behavioral change (Kaplowitz et al., 2009).

Such an education program could also harness the experiences of the target groups to design messages that could facilitate their interpretation of life experiences in an environmentally benign manner. Education programs designed this way, we believe, would help strengthen pro-environmental PN, which this study shows is an important precursor of ECB and EAB among the populace. At the same time, such a program could foster development of pro-environmental social norms that may subsequently pressure others to act in environmentally benign manners because of social modeling (Mattis et al., 2009; Mikulincer and Shaver, 2005). Members of the institution join the university with a wide range of life experiences, personal characteristics, and antecedents or determinants of environmental awareness and concern. It would be informative to explore how useful specific program designs and program 
elements can be at promoting institutional sustainability across individuals with different backgrounds and experiences. Doing so may provide useful insights into programmatic interventions for increased institutional sustainability.

Additionally, in corroboration with previous studies (Abrahamse, 2007; Ibtissem, 2010), our results demonstrate an attenuated effect of the VBN constructs on ECB. It is possible that, unlike other pro-environmental behavior, ECB is primarily undertaken independently of environmental considerations. This could imply that programs aimed at promoting behavioral change related to energy use in an institutional setting may need to account for factors other than environmental considerations - such as convenience and direct economic benefits - in their design to have the greatest impact. Also, it may be necessary that future research on the determinants of ECB integrate some external or contextual factors into the VBN model to improve its predictive power of energy use activities.

\section{Acknowledgments}

This study was sponsored by a grant from the Office of the Vice President of Finance and Operation at Michigan State University. We thank Aimee Wilson for the research assistance. We are also grateful to Drs. Frank Lupi and Laurie Thorp for their assistance throughout the data collection phase, the anonymous reviewers for their constructive feedback, and all study participants for their support.

\section{References}

AAPOR (American Association for Public Opinion Research). (2009). Standard definitions: Final dispositions of case codes and outcome rates for surveys. AAPOR.

Abrahamse, W. (2007). Energy conservation through behavior change: Examining the effectiveness of a tailor-made approach (Unpublished doctoral dissertation). Faculty of Behavioral and Social Sciences, Groningen University, The Netherlands.

Abrahamse, W., Steg, L., Vlek, C., \& Rothengather, T. (2007). The effect of tailored information, goal setting and tailored feedback on household energy use, energy-related behaviors and behavioral antecedents. Journal of Environmental Psychology, 27, 265-276. 
Andersson, L., Shivarajan, S., \& Blau, G. (2005). Enacting ecological sustainability in the multinational corporation: A test of an adapted value-belief-norm framework. Journal of Business Ethics, 59, 295-305.

Baker, R., Blumberg, S. J., Brick, J. M., Couper, M. P., Courtright, M., Dennis, J. M., ... Lavrakas, P. J. (2010). Research synthesis: AAPOR report on online panels. Public Opinion Quarterly, 74(4), 711-781.

Baron, R. M., \& Kenny, D. A. (1986). The moderator-mediator variable distinction in social psychological research: Conceptual, strategic, and statistical considerations. Journal of Personality and Social Psychology, 51(6), 1173-1182.

Bord, R. J., O'Connor, R. E., \& Fisher, A. (2000). In what sense does the public need to understand global climate change? Public Understanding of Science, 9, 205-218.

Bradford, J., \& Fraser, E. D. G. (2008). Local authorities, climate change and small and medium enterprises: Identifying effective policy instruments to reduce energy use and carbon emissions. Corporate Social Responsibility and Environmental Management, 15, 156-172.

Brown, M. A. (2001). Market failures and barriers as a basis for clean energy policies. Energy Policy, 29, 1197-1212.

Brown, T. A. (2012). Confirmatory factor analysis for applied research. New York: Guilford Press.

Clark, C. F., Kotchen, M. J., \& Moore, M. R. (2003). Internal and external influences of pro-environmental behavior: Participation in a green electricity program. Journal of Environmental Psychology, 23(3), 237-246.

Cook, C., Heath, F., \& Thompson, R. L. (2000). A meta-analysis of response rates in Web- or Internet-based surveys. Educational and Psychological Measurement, 60(6), 821-836.

Couper, M. P. (2008). Designing effective Web surveys. New York: Cambridge University Press.

Diekmann, A., \& Preisendörfer, P. (2003). Green and greenback: The behavioral effects of environmental attitudes in low-cost and high-cost situations. Rationality and Society, 15(4), 441-472.

Dietz, T., Fitzgerald, A., \& Shwom, R. (2005). Environmental values. Annual Review of Environmental Resources, 30, 335-372. 
Dillman, D. A. (2007). Mail and internet surveys: The tailored design method (2nd ed.). New York: John Wiley and Sons.

Dudley, W. N., Benuzillo, J. G., \& Carrico, M. A. S. (2004). SPSS and SAS programming for the testing of mediation models. Nursing Research, 53(1), 59-62.

Dunlap, R. E., \& Van Liere, K. D. (1978). The "new environmental paradigm": A proposed measuring instrument and preliminary results. Journal of Environmental Education, 9(4), 10-19.

Dunlap, R. E., Van Liere, K. D., Mertig, A. G., \& Jones, R. E. (2000). Measuring endorsement of the new ecological paradigm: A revised NEP scale. Journal of Social Issues, 56(3), 425-442.

Herring, H. (2006). Energy efficiency - A critical view. Energy, 31(1), 10-20.

Ibtissem, M. H. (2010). Application of value beliefs norms theory to the energy conservation behavior. Journal of Sustainable Development, 3(2), 129-139.

IPCC (Intergovernmental Panel on Climate Change). (2014). Climate change 2007: Synthesis report. Geneva, Switzerland: IPCC.

Jansson, J., Marell, A., \& Nordlund, A. (2011). Exploring consumer adoption of a high involvement eco-innovation using value-belief-norm theory. Journal of Consumer Behavior, 10, 51-60.

Jasti, S., Dudley, W. N., \& Goldwater, E. (2008). SAS macros for testing statistical mediation in data with binary mediators or outcomes. Nursing Research, 57(2), 118-122.

Kaiser, F. G., Hubner, G., \& Bogner, F. X. (2005). Contrasting the theory of planned behavior with the value-belief-norm model in explaining conservation behavior. Journal of Applied Social Psychology, 35(10), 2150-2170.

Kals, E., Schumacher, D., \& Montada, L. (1999). Emotional affinity toward nature as a motivational basis to protect nature. Environment and Behavior, 31, 178-202.

Kaplowitz, M. D., Hadlock, T. D., \& Levine, R. (2004). A comparison of web and mail survey response rates. Public Opinion Quarterly, 68(1), 94-101.

Kaplowitz, M. D., Yeboah, F. K., Thorp, L. G., \& Wilson, A. M. (2009). Garnering input for recycling communication strategies at a big ten university. Resource Conservation and Recycling 53, 612-623. 
Karp, D. G. (1996). Values and their effect on pro-environmental behavior. Environment and Behavior, 28(1), 111-133.

Kollmuss, A., \& Agyeman, J. (2002). Mind the gap: Why do people act environmentally and what are the barriers to pro-environmental behavior? Environmental Education Research, 8(3), 239-260.

Komarek, T. M., Lupi, F., \& Kaplowitz, M. D. (2011). Valuing energy policy attributes for environmental management: Choice experiment evidence from a research institution. Energy Policy, 39(9), 5105-5115.

Kotchen, M. J., \& Moore, M. R. (2007). Private provision of environmental public goods: Household participation in green-electricity programs. Journal of Environmental Economics and Management, 53, 1-16.

Lee, D., Kang, C., Lee, J., \& Park, S. (2005). Characteristics of exemplary altruists. Journal of Humanistic Psychology, 45, 146-155.

Maiteny, P. T. (2002). Mind in the gap: Summary of research exploring "inner" influences on pro-sustainability learning and behaviour. Environmental Education Research, 8(3), 299-306.

Mattis, J. S., Hammond, W. P., Grayman, N., Bonacci, M., Brennan, W., Cowie, S. A., ... So, S. (2009). The social production of altruism: Motivations for caring action in a low-income urban community. American Journal of Community Psychology, 43(1-2 ), 71-84.

Midden, C., Kaiser, F., \& McCalley, T. (2007). Technology's four roles in understanding individuals' conservation of natural resources. Journal of Social Issues, 63(1), 155-174.

Mikulincer, M., \& Shaver, P. (2005). Attachment security, compassion, and altruism. Current Directions in Psychological Science, 14, 34-38.

Milfont, T. L., Duckitt, J., \& Wagner, C. (2010). A cross-cultural test of the value-attitude-behavior hierarchy. Journal of Applied Social Psychology, 40(11), 2791-2813.

Neuman, K. (1986). Personal values and commitment to energy conservation. Environment and Behavior, 18(1), 53-74.

Nisbet, E. K., Zelenski, J. M., \& Murphy, S. A. (2009). The nature relatedness scale: Linking individuals' connection with nature to environmental concern and behavior. Environment and Behavior, 41(5), 715-740.

Nordlund, A. M., \& Garvill, J. (2002). Value structures behind pro-environmental behavior. Environment and Behavior, 34(6), 740-756. 
Nordlund, A. M., \& Garvill, J. (2003). Effects of values, problem awareness, and personal norm on willingness to reduce personal car use. Journal of Environmental Psychology, 23, 339-347.

Poortinga, W., Steg, L., \& Vlek, C. (2004). Values, environmental concern and environmental behavior: A study into household energy use. Environment and Behavior, 36(1), 70-93.

Preacher, K. J., \& Leonardelli, G. J. (2010). Calculation for the Sobel test: An interactive calculation tool for mediation tests. Retrieved from quantpsy. org/sobel/sobel.htm

Presser, S., Rothgeb, J. M., Couper, M. P., Lessler, J. T., Martin, E., Martin, J., \& Singer, E. (2004). Methods for testing and evaluating survey questionnaires. New Jersey: John Wiley \& Sons.

Scherbaum, C. A., Popovich, P. M., \& Finlinson, S. (2008). Exploring individuallevel factors related to employee energy-conservation behaviors at work. Journal of Applied Social Psychology, 38(3), 818-835.

Schultz, P. W., \& Oskamp, S. (1996). Effort as a moderator of the attitudebehavior relationship: General environmental concern and recycling. Social Psychology Quarterly, 59(4), 375-383.

Schultz, P. W., \& Zelezny, L. (1999). Values as predictors of environmental attitudes: Evidence for consistency across 14 countries. Journal of Environmental Psychology, 19, 255-265.

Schultz, P. W., \& Zelezny, L. (2003). Reframing environmental message to be congruent with American values. Research in Ecology, 10, 126-136.

Schwartz, S. H. (1977). Normative influences on altruism. Advances in Experimental Social Psychology, 10, 221-279.

Schwartz, S. H. (1992). Universals in the content and structure of values: Theoretical advances and empirical tests in 20 countries. Advances in Experimental Social Psychology, 25, 1-65.

Schwartz, S. H. (1994). Are there universal aspects in the structure and contents of human values? Journal of Social Issues, 50(4), 19-45.

Sheehan, K. B. (2001). E-mail survey response rates: A review. Journal of Computer-Mediated Communication, 6(2). doi: 10.1111/j.1083-6101.2001. tb00117.x 
Steg, L., Dreijerink, L., \& Abrahamse, W. (2005). Factors influencing the acceptability of energy policies: A test of VBN theory. Journal of Environmental Psychology, 25(4), 415-425.

Steg, L., \& Vlek, C. (2009). Encouraging pro-environmental behaviour: An integrative review and research agenda. Journal of Environmental Psychology, 29(3), 309-317.

Stern, P. C. (2000). Towards a coherent theory of environmentally significant behavior. Journal of Social Issues, 56(3), 407-424.

Stern, P. C., \& Dietz, T. (1994). The value basis of environmental concern. Journal of Social Issues, 50(3), 65-84.

Stern, P. C., Dietz, T., Abel, T., Guagnano, G. A., \& Kalof, L. (1999). A value-beliefnorm theory of support for social movements: The case of environmentalism. Human Ecology Review, 6(2), 81-97.

Stern, P. C., Dietz, T., \& Guagnano, G. A. (1998). A brief inventory of values. Educational and Psychological Measurement, 58, 884-1001.

Stern, P. C., Dietz, T., \& Kalof, L. (1993). Value orientations, gender and environmental concern. Environment and Behavior, 25, 322-348.

Stern, P. C., Dietz, T., Kalof, L., \& Guagnano, G. A. (1995). Values, beliefs and pro-environmental action: Attitude formation towards emergent attitude objects. Journal of Applied Social Psychology, 25(18), 1611-1636. 
This text is taken from Human Ecology Review, Volume 22, Number 2, 2016, published 2016 by ANU Press, The Australian National University, Canberra, Australia. 